\title{
O PROFESSOR E O ATO DE ENSINAR
}

ELIZABETH TUNES

Faculdade de Educação da Universidade de Brasília

bethtunes@globo.com

MARIA CARMEN V. R. TACCA

Faculdade de Educação da Universidade de Brasília

mctacca@brturbo.com

\section{ROBERTO DOS SANTOS BARTHOLO JÚNIOR}

Instituto Alberto Luz Coimbra de Pós-Graduação e Pesquisa de Engenharia da

Universidade Federal do Rio de Janeiro

roberto.bartholo@capes.gov.br

\section{RESUMO}

A sala de aula é o espaço privilegiado de negociações e de produção de novos sentidos e significados a respeito, principalmente, dos diferentes conceitos escolares. Isso acontece em uma rede interativa complexa em que se tornam presentes e se atualizam a história de vida, as experiências e vivências de professores e alunos, além do próprio conhecimento formal. Do professor espera-se que conduza o seu grupo de alunos, buscando compreender e negociar os diferentes processos de significação que envolvem as situações de aprendizagem que planejou. Tem sido comum identificar o professor nesse papel de mediador, atribuindo a idéia à abordagem histórico-cultural. O objetivo deste texto é discutir a identificação entre ação docente e mediação, de modo a caracterizar aquilo a que corresponde, segundo nossa ótica, o trabalho desenvolvido pelo professor, tendo como foco o conceito de zona proximal de desenvolvimento. As considerações encaminham-se para o entendimento de que os conteúdos escolares somente estarão a serviço do desenvolvimento dos alunos se forem operados na conjuntura dos seus processos de significação, tendo em conta que a função primordial da educação é a de nutrir possibilidades relacionais.

PROFESSORES - RELAÇÕES PROFESSOR-ALUNO - PAPEL DO PROFESSOR - SALA DE AULA

\section{ABSTRACT}

THE TEACHER AND THE ACT OF TEACHING. The classroom is the privileged space for negotiation and production of new senses and meanings, especially concerning the different school concepts. This takes place within a complex interactive network where, besides for- 
mal knowledge itself, teachers' and students' life history and experiences become present and are updated. The teacher is expected to guide his/her group of students, aiming at understanding and negotiating the different meaning-making processes involved in the learning situations he/she has planned. The teacher has usually been identified with this mediator role, and this idea has been assigned to the historical and cultural approach. The objective of this text is to discuss the identification between teacher action and mediation, in order to characterize what the work developed by the teacher corresponds to according to our point of view, focusing on the zone of proximal development concept. The considerations suggest that learning contents will only be at the service of student development if they are operated taking into account the conjuncture of their meaning-making processes, and observing that the utmost role of education is to promote relational possibilities.

TEACHERS - STUDENT TEACHER RELATIONSHIP - TEACHER ROLE-CLASSROOMS

No convívio social, a experiência interpessoal possibilita o processo de elaboração e reelaboração de sentidos que organizam e integram a atividade psíquica dos participantes da relação. $\bigcirc$ movimento relacional cria múltiplas possibilidades de significação, construídas no momento próprio da relação, com caráter intersubjetivo. Do ponto de vista psicológico, a dinâmica relacional não é simples nem linear. Ao contrário, é um acontecimento vivo, contraditório e multidimensional, que pode direcionar a constituição de diferentes configurações da personalidade, ainda que esta guarde sempre uma unidade interna, uma relativa estabilidade. Existe, assim, uma dinâmica complexa entre o pessoal e o social, que só pode ser compreendida no contexto de mútuas e contínuas influências, o que faz aparecer novas reorganizações a partir dos sentidos subjetivos que surgem em cada experiência intersubjetiva (González Rey, 1997).

Ancorados nessas idéias podemos antever a importância de conceber o processo de ensino-aprendizagem como espaço de relação e delinear perspectivas analíticas interessantes. Um grupo de alunos e seu professor estão mergulhados em diferentes possibilidades interativas. A despeito de desempenharem funções inerentes a papéis que Ihes são reservados, e tidos como esperados, na instituição escolar estão em processo contínuo de criação intersubjetiva de significados que, por sua vez, podem gerar novas possibilidades de relação. Nesse processo, integram-se histórias de vida com inúmeras experiências e vivências, tornando-se presentes e se atualizando sentidos subjetivos. Isso não quer dizer, contudo, que os que ensinam e os que aprendem percebam, a cada instante, o impacto que sofrem e causam um no outro. Há que se ter em conta, entretanto, que o professor planeja ações cujos objetivos realizam-se no aluno. $\mathrm{Na}$ esfera de ações do professor, existe um impacto 
no aluno que é intencional e esperado como realização, fato que não se pode afirmar que existia da parte do aluno.

Assim, para o professor empenhado em promover a aprendizagem de seu aluno, há o imperativo de penetrar e interferir em sua atividade psíquica, notadamente seu pensamento. Essa necessidade antecede a tudo e, por isso mesmo, dirige a escolha dos modos de ensinar, pois sabe o professor que os métodos são eficazes somente quando estão, de alguma forma, coordenados com os modos de pensar do aluno. É nesse sentido, portanto, que podemos afirmar que o aluno dirige o seu próprio processo de aprender. Essa idéia é a que se apreende de Vigotski quando examina teoricamente as relações entre aprendizagem e desenvolvimento e formula o conceito de zona de desenvolvimento proximal (Vygotsky, 1987, 199I). Como esse conceito serve de reflexão a respeito do contexto educacional e da questão proposta sobre mediação pedagógica? Segundo essa ótica, o que podemos falar a respeito da relação professor-aluno?

Há muito tempo e para muitos, ao professor caberia o papel de jardineiro. Fertiliza-se o solo, semeia-se, mantém-se o solo úmido, protege-se o broto de pragas e ervas daninhas para que possa crescer saudável e mostrar seus frutos. Não se interfere na planta. É necessário apenas protegê-la das adversidades para que possa desenvolver em plenitude suas potencialidades naturais. Nada há o que deva limitar a semente. Essa é a metáfora que se pode fazer da educação permissiva, com excesso de relaxamento e indulgência. Uma outra visão, também compartilhada por muitos, admite o professor como uma espécie de escultor. A partir da pedra bruta, delinear e moldar formas reconhecíveis, estritamente conforme o plano gestado na imaginação do escultor. É claro que o material de que é feita a pedra bruta impõe algumas condições de limites para a ação do escultor. Limites estes, contudo, muito mais circunscritos aos instrumentos a utilizar do que propriamente ao que se pretende esculpir. $\bigcirc$ que importa, pois, é o que foi planejado; o projeto que dirige e justifica todas as ações e os meios a serem empregados. Nada mais há que deva impor restrições ao plano do escultor. Essa é a metáfora que se pode fazer da educação autoritária que desliza nos eixos da restrição e da compulsão (Buber, apud Murphy, 1988). Sobre cada uma das visões, podemos dizer que "o educador jardineiro não tem confiança suficiente; o escultor tem-na em excesso" (Murphy, 1988, p.90).

À primeira vista, ambas as formas de educação - a das tendências à liberdade e a do hábito do autoritarismo - são individualistas. A primeira confe- 
re pleno exercício ao "individualismo dos alunos por não estabelecer um ideal comum que limite suas diferenças pessoais, enquanto a segunda permite o livre reinado do individualismo do educador, cuja teoria, aparentemente, dá-Ihe o poder de moldar cada aluno à sua própria imagem. Mas essa segunda suposição, de nenhum modo, corresponde à verdade. Se cada professor pudesse confrontar seus alunos com um padrão particular a que ele quer que atendam, o resultado seria o caos, a desordem, e não o individualismo" (Buber, apud Murphy, 1988, p.90-91).

Em um dos textos em que examina o papel do aluno e o do professor, Vigotski faz afirmações aparentemente contraditórias. Diz ele, em um momento:

A rigor, do ponto de vista científico, não se pode educar a outrem [diretamente]. Não é possível exercer uma influência direta e produzir mudanças em um organismo alheio, só é possível educar a si mesmo, isto é, modificar as reações inatas através da própria experiência. (Vygotsky, 2003, p.75)

Em um outro ponto, afirma: "Por isso, o professor desempenha um papel ativo no processo de educação: modelar, cortar, dividir e entalhar os elementos do meio para que estes realizem o objetivo buscado" (idem, p.79). A nosso ver, a posição de Vigotski, apenas referida, não pode ser interpretada como se ele defendesse ora a educação pelo hábito do autoritarismo, ora a das tendências à liberdade. Um exame cuidadoso de sua obra, tendo em conta, especialmente, o conceito de zona proximal de desenvolvimento, mostra que as duas concepções de educação aqui indicadas não correspondem ao seu pensamento (Tunes, Bartholo Jr., 2004). Tomando como fio condutor algumas críticas desenhadas por Buber à visão progressista ou moderna da educação, conforme análise de Murphy (1988), é possível verificar que há, em Vigotski, uma terceira maneira de ver a ação educativa, pautada por uma orientação antropológica específica.

Uma das críticas tecidas por Buber, diz respeito ao que se entende por potencialidade individual. Para ele, "o ser humano é o ente apto ao relacionamento pessoal com a alteridade, o ser-em-relação" (Bartholo Jr., 200 I , p.77). Daí porque condena a prática reducionista de identificar as potencialidades criativas em termos de habilidades e energias específicas e de caracterizar a criatividade, essencialmente, como uma expressão do eu individual. Diz ele: 
Os psicólogos modernos são inclinados a derivar a multiforme alma humana de um único elemento primevo - a "libido", a "vontade de poder" e assim por diante. Mas isso é, na verdade, apenas a generalização de certos estados degenerados em que um único instinto não apenas domina como se espalha parasitariamente sobre os outros [...] Em oposição a essas doutrinas e métodos, que empobrecem a alma, precisamos continuamente indicar que a vida humana interna é, originalmente, uma polifonia em que nenhuma voz pode ser "reduzida" a uma outra e em que a unidade não é conseguida analiticamente, mas apenas ouvida na harmonia do presente. (Buber, apud Murphy, I988, p.91-92)

Para Buber, potencialidade e vida interna enraízam-se firmemente na vida de relação. Logo, a principal função da educação não poderia ser a de prover oportunidades para o crescimento e expressão do eu, mas, essencialmente, a de nutrir possibilidades relacionais.

Uma segunda crítica de Buber à visão moderna de educação diz respeito ao caráter e propósito da liberdade individual. Para ele, a educação moderna comete um equívoco e estabelece uma confusão quando escraviza a liberdade responsável, moralmente orientada, à liberdade de autodesenvolvimento e crescimento:

Há uma tendência a entender a liberdade, que poderia ser denominada de liberdade evolucionária, como o pólo oposto de compulsão, de estar dominado por uma compulsão. Mas no pólo oposto da compulsão não se encontra a liberdade mas a vida em comunhão. A compulsão é uma realidade negativa; a vida em comunhão, a positiva; liberdade é uma possibilidade, possibilidade reconquistada [...] A liberdade na educação é a possibilidade de comunhão; não pode ser dispensada nem empregada em si mesma; sem ela nada acontece, mas também nada acontece por meio dela... (apud Murphy, 1988, p.93)

Apartando-se das duas visões que critica, Buber vê o professor como alguém que demonstra uma visão dinâmica de afirmação da vida e realça o seu papel formativo, disciplinador e altamente intencional. $\bigcirc$ ensino é, fundamentalmente, diálogo: o importante, para o professor, não é falar do ou sobre o aluno, mas com o aluno, um diálogo verdadeiro que implica a aptidão daquele para o relacionamento pessoal com este, que é outro. Admitida como função primordial da educação o nutrir possibilidades relacionais, a relação professor- 
aluno deve, necessariamente, pautar-se na confiança mútua, na presença exemplar e na inteireza do professor, pela palavra, e na maneira com que o professor, efetivamente, promove métodos disciplinados, críticos e reflexivos de questionamento e indagação, que Buber considera essenciais para a aprendizagem e o conhecimento autênticos (Murphy, 1988).

A psicologia histórico-cultural de Vigotski concebe o psiquismo como uma construção social e encontra na mediação semiótica um conceito importante, que corresponde à idéia de intervenção de um terceiro elemento que possibilita a interação entre outros dois termos de uma relação (Sirgado, |991). Assim, o termo mediação é utilizado, no trabalho de Vigotski, para se referir aos sistemas de signos e ao papel que estes desempenham nas relações dos homens com o seu contexto social. Os seres humanos criam continuamente instrumentos e sistemas de signos, que Ihes permitem conhecer e transformar o mundo, ao mesmo tempo em que estes os transformam, impelindo o desenvolvimento de novas funções psíquicas. A expressão mediação semiótica refere-se, portanto, a um elo que se realiza com um sistema de signos, e que possibilita "pensar o psiquismo humano como um processo permanente de produção que envolve o indivíduo e seu mundo social numa interação constante" (Sirgado, 1991, p.48), revelando-se a natureza semiótica da constituição de seu psiquismo.

A promoção do desenvolvimento de funções psicológicas admite a anterioridade do processo de aprender, que acontece na relação com um parceiro mais capaz, que oferece a ajuda. Ajudar é possibilitar o fazer com; é dialogar, portanto. Se o ajudante for o professor, a ajuda é planejada e sistemática, pois o seu impacto no aluno é esperado como realização, conforme já dissemos. Logo, é preciso conhecer o que já há; novamente, o diálogo. Conhecer o que há para definir o que poderá ser. Nesse jogo assimétrico, professor e aluno ferem-se, atingem-se mutuamente. $\bigcirc$ aluno dirige o seu próprio processo de aprender, restringindo, ativamente, as possibilidades de ação do professor. Por seu turno, o professor é quem planeja e cria as condições de possibilidade de emergência das potencialidades do aluno, como querem, em acordo, Buber e Vigotski: criador que cria a criatura em liberdade. Liberdade não como meio ou como fim, mas como parte constitutiva do ato mesmo de criação. Por isso, pode-se deduzir que, também para Vigotski, educar é nutrir possibilidades relacionais. Nessa perspectiva, ensinar e aprender traduzem-se num encontro que revela e que compromete. "Se, do ponto de vista científi- 
co, negamos que o professor tenha a capacidade mística de 'modelar a alma alheia', é precisamente porque reconhecemos que sua importância é incomensuravelmente maior" (Vygotsky, 2003, p.76).

Encontramos, então, o momento de falar em mediação pedagógica. Tem sido comum atribuir a Vigotski a idéia de que o professor tem um papel mediador; um elo entre o conhecimento e o aluno. Queremos trazer esse conceito para a discussão e contestar sua adequação ao pensar a atividade do professor na perspectiva histórico-cultural. Se, no processo do ensinar e do aprender, o aluno sempre se antecipa como oferta, na situação dialógica, interferindo efetivamente com restrições nas possibilidades de ação do professor, este não passa "em brancas nuvens" pela relação. Logo, não pode ser concebido como um mero elo intermediário, um negociador que, em princípio, permaneceria o mesmo pós-negociação. Nem o aluno, nem o professor são os mesmos depois do diálogo. O processo de ensinar e aprender, visto como unidade, parece, de fato, constituir um desafio à permanência da mesmice. A função instrumental do professor como mediador do conhecimento para o aluno carrega, a nosso ver, as duas concepções de educação a que se aludiu anteriormente e que tanto Buber quanto Vigotski criticam.

O conceito de internalização de funções psíquicas superiores, formulado por Vigotski e que se traduz na lei geral de desenvolvimento psíquico, reforça a nossa posição. A cultura e seus sistemas simbólicos, semióticos alcançam a condição de intrapsicológicos passando, necessariamente, por processos interpsicológicos. Assim, ganham relevância as ações sociais que permitem aos indivíduos compartilharem a complexa rede de significados socialmente produzidos. Portanto, é na situação interpsicológica que brota o significado da relação pedagógica. Estão aí circunscritas, a um espaço relacional, as ações do professor e do aluno.

Ao se examinar o conceito de mediação fica evidente sua complicação e incompletude para se compreender o papel do professor. Ainda que seja possível admitir-se o professor como mediador do conhecimento para o aluno, isso não esgotaria sua função, nem daria conta do que lhe é primordial. $\bigcirc$ professor é uma pessoa vulnerável à alteridade do aluno. Assim, trabalho pedagógico e zona de desenvolvimento proximal não significam outra coisa que não ação conjunta. $O$ desenvolvimento psicológico é resultado de algo que acontece no espaço da relação professor e aluno, como possibilidade de realização futura. "O que caracteriza o desenvolvimento proximal é a capacidade 
que emerge e cresce de modo partilhado" (Góes, 1991, p.20). Portanto são necessárias parcerias nos espaços pedagógicos para que haja a possibilidade de empreendimento de novas situações sociais de desenvolvimento.

Como ilustração, introduzimos neste texto a fala de duas professoras que mostram as formas pelas quais são instituídas as interações com seus alunos. Uma delas pensava sua turma de forma bastante coletivizada, o que a fazia perder de vista os alunos concretos da sala de aula. Quando desenvolveu uma atividade específica com um grupo pequeno de alunos, surpreendeu-se com a revelação de um deles e assim se pronunciou:

E eu estava te dizendo que descobri um lado do Elizer que eu não conhecia... Ele tem idéias assim tão maduras quando você conversa com ele. Porque você olha, ele, aquela coisinha largada lá no canto... ele não participa... não se pronuncia, deixa de fazer metade das atividades. E você acha que é um menino com muito mais dificuldade do que apresenta. Quando vai conversar com ele... você descobre um lado tão maduro, com idéias, assim, a respeito da vida, das coisas, que fiquei impressionada. Os interesses dele são bem outros, ele... pode ter lá as suas dificuldades, mas tem um lado que eu desconhecia, que é a forma como vê o mundo, as coisas, o que pensa em termos de... você viu naquele dia? $\bigcirc$ futuro, que ele falou. Conversei com ele depois. $\bigcirc$ que pensa a respeito desse mundo... o futuro dele. Conversando comigo... eu fiquei impressionada com os sonhos dele, os projetos para o futuro, e questionei: "Como é que você pensa em conseguir tudo isso se você às vezes é incapaz de fazer sua tarefa de pura malandragem? Capacidade intelectual você tem. Você é um menino inteligente". Ele olhou bem pra mim e falou: "Você me acha inteligente?". Eu falei: "Acho. Você é inteligente e eu estou conversando com você porque está me dando provas de que é inteligente. Porque você não faz as coisas? Por que não pergunta quando tem dúvida?". "Ah, porque eu tenho vergonha".

Percebe-se que a composição coletiva da turma, para a qual os professores acabam dirigindo-se quase que exclusivamente, chega a dificultar a vida escolar de algumas crianças. Sobre elas, às vezes bastaria uma atenção especial, um momento compartilhado, para que fossem entendidos aspectos de seu percurso de desenvolvimento, o que possibilitaria propor a ajuda necessária, instigando o próximo passo. 
Uma outra professora também tinha um grupo a quem precisava atender em primeiro lugar. Sua atuação pedagógica permitia-lhe contudo sair das amarras do coletivo e procurar o encontro com alguns alunos em especial. Desconfiava das informações que recebia e colocava-se na posição de interagir com cada um de seus alunos, para que pudesse avaliá-los adequadamente. Talvez, por isso, falasse da sua turma de forma cuidadosa:

...porque quando eu recebi a turma, e... "Ah, você está com fulano, você está com ciclano", as pessoas acabam fazendo essa avaliação "... É assim, é assado". E eu acho horrível, porque... na primeira semana, uns 15 dias depois... Bom, aquele menino não é nada assim... Porque vai do que a pessoa... vai do professor. Então... eu não vi nada do que muitas pessoas falaram pra mim. É uma coisa normal que você tem que... o desafio está aí, você tem que... arranjar a melhor maneira para que ele aprenda.

Em conclusão, podemos dizer que a compreensão que o professor tem do aluno e do que deve realizar com ele tem muitas implicações para o seu trabalho. Cabe-Ihe permitir que o aluno revele-se por si, mostre-se naquilo que pede como ajuda. Para isto o que the compete fazer? A nosso ver, seu papel desdobra-se em muitas funções que devem ser descobertas e assumidas conforme o fluxo do desenvolvimento do aluno. E o professor é o organizador do ambiente social (conforme escreveu Vygotsky, 2003), que é o fator educativo por excelência. É por isso que ele enfatiza a posição do aluno como aquele que dirige o seu próprio processo de aprendizagem.

Assumir-se como professor requer a clareza de muitos aspectos constituintes da missão a ser realizada. É preciso, sim, ter metas e objetivos, saber sobre o que se vai ensinar, mas não se pode perder de vista, um segundo sequer, para quem se está ensinando e é disso que decorre o como realizar. Integrar tudo inclui dar conta de diversas facetas do processo ensino-aprendizagem, ou seja, a do aluno concreto, real, a do conhecimento, a das estratégias de ensino, e a do contexto cultural e histórico em que se situam (Tacca, 2000). Conjugar isso exige compromisso e responsabilidade com o aluno, o que permite avançar na exigência da compreensão da pessoa no processo de ensinar e aprender. 


\section{REFERÊNCIAS BIBLIOGRÁFICAS}

BARTHOLO Jr., R. Você e eur. Martin Buber, presença palavra. Rio de Janeiro: Garamond, 2001 .

GÓES, M. C. R. A Natureza social do desenvolvimento psicológico. Caderno CEDES, Campinas, n.24, p.21-29, 1991. [Pensamento e linguagem: estudos na perspectiva da psicologia soviética]

GONZÁLEZ REY, F. Epistemologia cualitativa y subjetividad. La Habana: Pueblo y Educación, 1997.

MURPHY, D. Martin Buber's philosophy of education. Dublin: Irish Academic Press, 1988.

SIRGADO, A. P. O Conceito de mediação semiótica em Vygotsky e seu papel na explicação do psiquismo humano. Caderno CEDES, Campinas, n.24, p.38-51, 1991. [Pensamento e linguagem: estudos na perspectiva da psicologia soviética]

TACCA, M. C. V. R. Ensinar e aprender. análise de processos de significação na relação professor $\times$ aluno em contextos estruturados. Brasília, 2000. Tese (dout.) Universidade de Brasília.

TUNES, E.; BARTHOLO Jr., R. Da Constituição da consciência a uma psicologia ética: alteridade e zona proximal de desenvolvimento. In: SIMÃO, L. M.; MARTINEZ, A. M. (orgs.) O Outro no desenvolvimento humano: diálogos para a pesquisa e a prática profissional em psicologia. São Paulo: Pioneira; Thomson Learning, 2004. p.4I-60.

VYGOTSKY, L. S. A Formação social da mente. São Paulo: Martins Fontes, 1991.

. Problems of general psychology. In: RIEBER, R. W.; CARTON, A. S. The Collected works of L. S. Vygotsky. New York: Plenum, 1987. v. I, p. 39-285.

. Psicologia pedagógica. Porto Alegre: Artmed, 2003.

Recebido em: março 2004

Aprovado para publicação em: janeiro 2005 